\title{
Promising Areas for Developing HR Managers' Competencies in the Digital Age
}

\author{
V.A. Kapitanov ${ }^{1}$, O.S. Osipova ${ }^{2, *}$, and L.S. Chikileva ${ }^{2}$ \\ ${ }^{1}$ Polyus Research Institute of M.F. Stelmakh, Moscow, Russia \\ ${ }^{2}$ Financial University under the Government of the Russian Federation, Moscow, Russia
}

\begin{abstract}
The rapid development of technologies is creating a new digital reality in human resource management. In the context of the transition to the digital economy and transformation of traditional classical organizations to digital ones, digital management decentralization will take place on the basis of digital technologies. The most important characteristic feature of a digital organization is interaction of the HR service with employees using mobile applications. Predictive HR analytics, employee-centered professional training, feedback not only at the vertical level but also at the horizontal level requires the development of new competencies of HR specialists. Based on the authors' research, implemented by a temporary creative team, the practice of developing managerial competencies in the process of digital transformation is analyzed using the example of HR management services in organizations at different levels of digital maturity. The study has shown understanding on the part of HR specialists that automation has a significant potential and will be in demand in all the companies, regardless of their size. The transition from a traditional organization to a digital one will require changes in the qualification requirements for HR specialists, readiness of HR specialists to acquire new digital competencies, to develop their professional skills and personal abilities.

Keywords: competencies, skills, digital transformation, HR department, HR management service, organizational development
\end{abstract}

\section{Introduction}

In recent years many articles have appeared in the scientific literature on the specifics of the functioning of HR systems in the context of digital transformation [1-5], highlighting the changing role of HR services in the era of digitalization [6]. Human resource management in the digital economy is considered in them as one of the key business processes that directly affects the increase in labor productivity [7-9]. Many scholars have turned directly to the analysis of the digitalization of the HRM system [10-12, 4, 13], to the growing role of HR analytics [14].

The transition to digitalization is a new stage in the development of the HR industry, which imposes new requirements on the competence model of HR specialists, who must

*Corresponding author: ososipova@fa.ru 
increasingly use modern digital tools. Scientists develop the typology of personnel competencies for Industry 4.0. For example, E. Flores, X. Xu, and Y. Lu [15] have introduced a new term "workforce architecture", covering the human capital of the future, and suggested a new typology of personnel competencies for Industry 4.0 . This article draws attention to important changes in human capital in the future of Industry 4.0 and offers a human-centered perspective for companies in the new industrial revolution. The interdisciplinary research is based on literature review. However, there are few studies devoted to the new holistic model of competencies of HR specialists. The most advanced area of research in relation to HR services is the study of the evolution of digital competencies of HR employees in the field of recruitment. Analytical works that summarize the first results of the digital transformation of organizations and HR departments are of particular scientific value. Of note is the study of A. DiRomualdo, D. ElKhoury and F. Girimonte [16], in which the authors, using the Hackett Group's extensive database with paid HR benchmarks with Global 1000 companies, show how digital technologies will change HR processes and organizational structure. They emphasize the need to create new roles in HR. The authors pay attention to the fact that HR organizations should plan the changes needed for meeting the requirements of the digital transformation of the enterprise. The article presents some recommendations for the transformation of HR departments at the initial stage of digital transformation $[17,18]$.

In general, we can talk about a high degree of readiness of Russian HR specialists to automate their work functions, and a significantly higher level of digital literacy of employees of HR departments compared to the staff of organizations as a whole. As recent research shows, Russian HR specialists are able to master digital skills quickly enough [19]. However, there is an imbalance in terms of the training of HR specialists in the field of digital literacy and understanding of the functioning of new business models, especially among the older generation of HR. This is what makes us more closely examine the dynamics of the competence model of HR managers in the process of increasing digital maturity of organizations. The relevance of this article is due to the lack of knowledge of the processes that allow us to come close to developing a model of competence of HR specialists at various levels of digital maturity of organizations.

\section{Research Questions}

1. How will the transition from a traditional to a digital organization affect the work of HR managers, the demand for individual skills and abilities?

2. What professional HR-technological and technical competencies do HR specialists plan to acquire/improve?

3. What personal and practical skills do HR-managers plan to get/improve to enhance their professional competence?

Purpose of the Study - to summarize the directions and forms of competence development demanded by HR specialists in the conditions of digitalization of Russian companies.

\section{Methodology}

The theoretical and methodological basis of this research is the modern understanding of the theory of human capital in the context of the concept of sustainable development, the concept of human development and the concept of decent work. The following methods are used in the research: comparative, logical and methods of statistics. The results of analytical and sociological research, the results of expert surveys are used in the paper. To determine 
the key drivers of changes, opportunities and limitations of organizations ' human resource management systems in the context of digitalization of the economy, the temporary creative team conducted an original HR survey among specialists responsible for personnel management in organizations operating in the Russian Federation from June 4 to June 26, 2019. The questionnaire was developed on the basis of a review of information from domestic and foreign sources, summarizing the results of expert surveys of IT and HR specialists, and was highly appreciated by experts. The questionnaire consisted of 5 blocks, one of which was devoted to the prospects for the development of the HR service in the context of digital transformation. The survey was conducted remotely using the GoogleDocs form editor. Subsequently, the received data were processed using the Excel program. 152 people who represent different sectors of the economy were interviewed. Respondents represented more than 20 regions of Russia. One in four respondents represented the service sector, including such highly digitalized industries as banking and Finance; media and e-commerce, IT and telecommunications; and one in three represented transport, logistics and distribution. 29\% of the respondents represented organizations with more than 10,000 employees, and one in four represented - between 1,000 and 10,000 employees. Such large organizations are expected to be the most automated, according to experts from SAP CIS and Deloitte. Almost one in three respondents noted that their organizations have achieved mature automation or laid the foundations for intelligent HR. Thus, we had a unique opportunity to trace the emergence of new trends in Russian HR management, and for the first time systematically summarize the Russian experience in the field of digitalization of not only organizational HR processes, but also the HR departments. This article analyzes the results of one of the questionnaire blocks (Section 5 . The Future of the digital organization's HR service). $64.05 \%$ of respondents work in departments called "Human Resources Management", 11.76\% - "Human Resources Department", 8.5\% -"Human Resources Management".

In accordance with the official affiliation, $68.42 \%$ of the respondents were HR managers, Heads of HR Departments - $24.34 \%$, HR partners, HR Directors - 7.24\%. The gender distribution of respondents was as follows: females $-74.34 \%$, males $-25.66 \%$.

The average age of the respondents was 35 years. It corresponds to the all-Russian indicators of the age of HR specialists. Every second male surveyed belongs to the older age group, this is a "trace" of the Soviet tradition, when the personnel departments preferred to hire retired military personnel. The vast majority of respondents $92.76 \%$, have higher education, $1.97 \%$ and $3.95 \%$ have secondary specialized and academic degrees respectively. $36.18 \%$ of respondents have work experience in the service that provides personnel management processes ranging from 3 to 10 years, $26.32 \%$ of respondents have more than 10 years of experience, and $23.03 \%$ - from 1 to 3 years. The group of HR employees with experience up to 1 year was $14.47 \%$.

\section{Results}

The results of our research have shown that there is an uneven involvement of Russian organizations in the process of digital transformation. Almost every second respondent noted that automation of HR processes is mostly relevant for the vast majority of large and medium-sized Russian companies seeking optimization, and only one in four respondents believes that automation is the best way for the vast majority of large companies. About $40 \%$ of respondents chose the answer "all the companies are equal in the process of digitalization, no matter what their size is - large, medium or small". Nearly every third person believes that automation of HR processes is also relevant for virtual organizations, 
as the emergence of new software products opens up opportunities for managing remote employees.

Respondents note that digitalization in HR is necessary primarily to get rid of routine (71\%); to improve access to the best labor resources using digital communication channels - $46.7 \%$, to develop remote forms of work (attracting staff from everywhere, at any time $38.8 \%$ ), to increase flexibility and individualization of people management $-37.5 \%$.

The transition from a traditional organization to a digital organization, according to respondents, will affect the work of HR managers to change the qualification requirements for HR specialists (according to 56.6\% of respondents). Every fourth respondent believes that the role of the HR service will increase, the institution of HR business partnership will not lose its importance, and the main competence of internal HR will be strategic thinking $(24.3 \%)$.

To understand in what direction HR-specialists competency model HR-specialists should develop, first of all it is necessary to answer a crucially important question: in which direction the development of functionality of the HR specialists will go. $34.9 \%$ of respondents believe that HR managers will be experts with a broad range of competences. Three times less respondents assume a different development of events - there will be more highly specialized HR experts (13.8\%). The answers to questions from 64 to 66 of the Questionnaire prove the orientation to a broad profile of the development of HR competencies. It is of great importance for the respondents to master a diverse range of new professional competencies that are necessary for the organization's transition to new business models and management of organizational development processes.

Among the professional HR-technological competencies that modern HR specialists would like to improve, the position of strategic HR has undoubtedly taken the leading place. It absolutely correlates with the answers to the previous question. Every second respondent has noted that in order to improve the efficiency of the HR manager's work, it is necessary for him / her to know in which direction the organization is going to develop, and how important is to switch to a new business model. Without analyzing characteristic features of strategic management, HR specialists can neither perform such a professional function as organizational development, nor plan their career growth. As noted above, it has become clear that HR managers can actually claim the position of partner, one of the top positions in digital organizations. $27.6 \%$ of respondents would like to acquire or improve their competence in developing organizational culture. Respondents identified change management, employee training and development, the ability to organize project and team work, and electronic document management as the second most promising group of competencies. Almost every third respondent would like to improve such competence as HR branding development.

For the first time, the desire of HR specialists to develop such competencies as managing employees ' emotions and impressions (20.4\%) came as close as possible to the desire to develop their competencies in managing candidate / employee evaluation processes $(22.4 \%)$. In previous years, the latter type of competence clearly led the way, as well as the desire to improve their skills in remuneration management. Almost one in seven respondents would like to learn how to create employees positive experience (14.5\%). As early as 2019 , HR specialists were clearly aware of the need to improve their skills in organizing fundamentally new forms of work with employees. $17.8 \%$ of respondents were in favor of acquiring or improving their skills in organizing flexible forms of employees' employment. One out of four respondents would like to study the management of remote employees and freelancers - $23 \%$, to understand the specifics of working with virtual organizations $-7.2 \%$.

It is important to note the demand for the development of such competencies as building the organizational architecture of the company - $15.1 \%$ and the ecosystem of the 
organization - $19.1 \%$. The study has proved that HR specialists respond quickly to the challenges of the time and are ready to master new methods of work that allow to increase the level of digitalization of HR departments. Answering the question № 60 "How will the transition from a traditional organization to a digital organization affect the work of HR managers?" almost every tenth respondent noted that the main competence of an HR manager will be the ability to make an employee happy $-9.2 \%$.

Question №64 of the questionnaire allowed us to specify the statement "what professional technical skills you would like to acquire / improve". The responses were distributed as follows. Half of the respondents would like to improve their skills in working with electronic document management. Such demand for the development of these skills is explained, in our opinion, by the fact that HR specialists from organizations at various levels of digital transformation took part in the survey.

At the same time, a significant proportion of respondents have demand for the acquisition / development of fundamentally new competencies. The demand for developing such skills as digital design in HR is leading (45\%), while working with corporate IT platforms is in the second place $(43.4 \%)$. This is followed by the demand for such a new competence as data collection, processing and analysis in real time, in other words, HR analytics $-41.5 \%$. Almost the same number of HR managers would like to improve their competencies by using specialized software to implement the HR function - $41 \%$. The control questions confirmed the high reliability of the data obtained: from 41 to $44,7 \%$ of the respondents were in favor of getting these skills.

The second most popular group of technical skills included: working with cloud technologies $-33 \%$, working in social media / networks $-32.2 \%$, digital security $-29 \%$. One in four respondents wants to improve their skills in working with mobile apps. Every sixth respondent who has taken part in our survey considers it appropriate to involve HR Department employees in the development of the Intranet design and interface. In the age group from 20 to 25 years, one in four respondents has chosen this answer. $22.8 \%$ of the HR specialists surveyed would like to improve their skills in advanced data visualization and processes.

In the course of the study, the demand for HR specialists to develop their professional personal and user skills was analyzed. Answering the question № 66 "What professional personal and user skills would you like to acquire " $43.4 \%$ of respondents expressed a desire to have digital creativity, $29.6 \%$ - the formation, development and promotion of a digital personality (personal digital profile), as well as the development of digital empathy $13.8 \%$. One in three respondents would like to improve their stress tolerance. Respondents strive to improve user's skills such as working in Photo Shop and similar image editors $(39.5 \%)$, learn more about personal security when using smart devices $(28.9 \%)$, and master the production of multimedia content for the Internet $(27 \%)$. Along with the skills mentioned above, basic skills such as typing speed and the use of mobile communication tools remain quite popular $-23 \%$ for both answers.

For the convenience of simultaneous perception of some important new areas of development of HR managers ' competencies, the frequency of responses is shown in Figure 1 . 


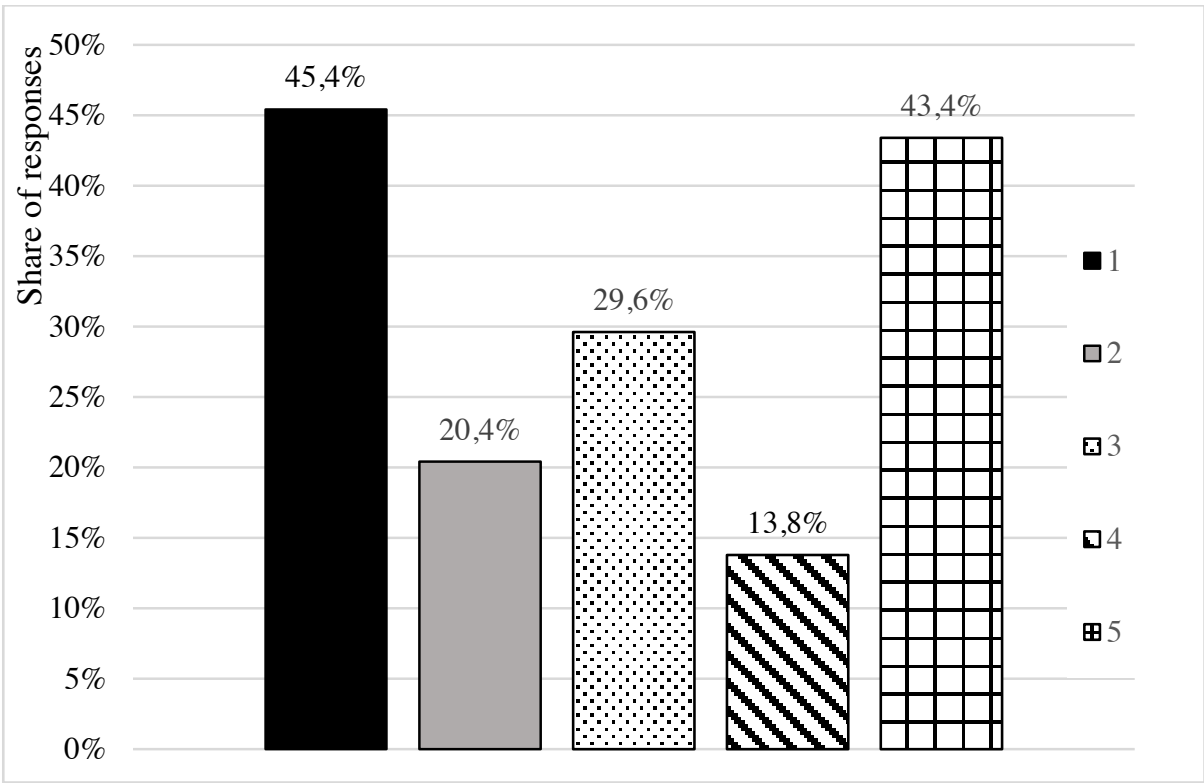

Fig. 1. Promising areas of development of HR managers' competencies identified in the survey of HR specialists. (All the questions involved choosing one or more answers from several options).

1. Question № 64: "What professional technical skills would you like to acquire/improve?" Answer option 1: "digital design in HR"

2. Question № 65:" What professional HR-technological competencies would you like to acquire/improve?» Answer option 21: "managing employee emotions and impressions".

3. Question № 66: "What professional, personal and user’s skills would you like to acquire/improve?" Answer option 2: "formation, development and promotion of a digital personality (personal digital profile)".

4. The same question. Answer option 3: "digital empathy".

5. The same question. Answer option 4: "digital creativity". Source: Own processing.

Four out of five consider that competencies are directly related to digital technologies. The respondents ' responses show that they are not only very interested in developing professional HR competencies for the implementation of their work functions, but are also ready to continuously improve their technical skills. All the respondents expressed their willingness to improve their digital literacy if needed, with $27.5 \%$ - paying their own money. Experts do not consider the system of professional retraining as the weakest link that hinders the development of software and digital competencies. However, almost every second respondent believes that the system of retraining / advanced training should be improved. Moreover, every fifth respondent believes that the process of retraining should become continuous (19.7\%). 36.2\% of respondents noted the need to develop mentoring by more IT-advanced employees, $22.4 \%$ support the idea of getting acquainted with the experience of software implemented in other companies. Every fourth believes that digitalization will allow to simulate a virtual reality for the training of workers $-24.3 \%$. 


\section{Discussion}

The increase in the speed of information transfer in the era of computerization at the turn of the Millennium has led to the centralization of organizational management systems, the transition to international quality standards, and the unification of management principles and algorithms. This process includes functional structuring of HR services, specialization of HR managers, development of competence approach and unification of their generalized labor functions within the framework of accepted professional standards. During this period, organizations with varying degrees of intensity have been automating operational HR processes, developing digital competencies for software development, as well as professional specialization of specialists in the main areas of HR departments.

The transition to a new stage of digitalization associated with a further increase in the speed of information and the need for organizations to switch to new business models requires a qualitative revision of the existing model of competence of HR managers.

The conducted sociological research allows us to declare that it is necessary to develop a new model of competencies for HR specialists. This model should be adapted to different levels of digital maturity of HR services. The formation of digital competencies for HR managers is reaching a fundamentally new level of development.

The transition to a new stage of digitalization associated with further increase in the speed of information and the need for organizations to switch to new business models requires a qualitative revision of the existing model of competence of HR managers.

The conducted sociological research makes it possible to declare that it is necessary to develop a new model of competencies for HR specialists. This model should be adapted to different levels of digital maturity of HR services. The formation of digital competencies for HR managers is reaching a fundamentally new level of development.

Modern HR technologies allow you to personalize your interaction with the staff. Large-scale hi-tech exhibitions and technology showrooms held in Russia in recent years show a geometric growth in the introduction of digital technologies in the work of HR services. Every year the scale of digital technologies introduced into the practice of HR work increases. At the fifth HR\&Technology Expo 2020, a system platform that gathers the most advanced and effective IT tools for personnel management, more than $70 \mathrm{HR}$ products will be presented this year, and more than 40 applied presentations by representatives of leading Russian and international companies actively implementing digital technologies will be announced. More than $50 \mathrm{HR}$-Tech experts will take part in the discussions. It is planned to discuss issues related to HR technologies and the evolution of HR functions. Within the framework of HR exhibitions, managers working with people in organizations will not only exchange useful solutions in the field of digitalization of HR functions, but also get the opportunity to test new products from leading IT developers of HR products. Traditionally, the greatest professional interest of the HR community is aroused by the CR digital technology Laboratory, a platform that directly unites HR specialists and developers of HR technologies.

All this creates favourable conditions for rethinking the directions of development of the competence model of HR specialists. Currently, issues of HR Analytics and data management, user's experience, working with vendors and IT teams come to the fore. We are actively implementing marketplaces, services and CRM to automate recruitment, and introducing virtual assistants to implement a number of HR functions-chatbots with artificial intelligence for HR processes in the company. Optimization of recruitment budgets and qualitative evaluation of candidates is based on the introduction of technologies with machine learning, cognitive computing and other data analysis solutions. Automation and e-learning are actively implemented: training, evaluation and staff development. When building a model of HR specialists' competencies in the context of 
continuous training, an optimal balance of digital, professional and "soft" skills is required, taking into account the multi-level model of digitalization of HR services.

\section{Conclusion}

In conclusion it should be mentioned that every second respondent believes that it is necessary to improve the system of retraining/advanced training of employees of HR departments. This work should be carried out taking into account the perspective directions of development of the model of competence of HR specialists. During the research, special attention was paid to finding out the subjective vision of HR managers of promising areas for the development of their professional and personal competencies. In recent years, you can often hear such a question: "What will happen to HR?" The answer is: "HR is being transformed". The results of the study have shown the results of this transformation within the competence approach. HR specialists quickly respond to the challenges of the time and are ready to master new methods of work to upgrade the level of digitalization of HR departments. The conducted research has made it possible to determine what competencies of HR specialists are the most important for them today, what is the degree of their development in organizations that are at various stages of digital transformation. More than that, we can identify the degree of demand for fundamentally new skills and abilities necessary for HR specialists to perform their work functions in the context of organizational digital transformation. A significant proportion of respondents are in favor of the acquisition/development of fundamentally new competencies, including the development of skills, such as digital design in HR and management of employees' emotions. The interviewed HR specialists have expressed a desire to develop digital creativity, a personal digital profile, and the development of digital empathy.

\section{Acknowledgements}

The reported study was funded by RFBR (Russian Foundation for Basic Research), project number 19-010-01042

\section{References}

1. M. Al-Mekhlal, L. Abu Romman, B. A. Al-Saqer, A comprehensive usability evaluation of an online HR system. In Blashki, K. \& Xiao Y. (Eds.), MCCSIS 2018 - Multi Conference on Computer Science and Information Systems. Proceedings of the International Conferences on Interfaces and Human Computer Interaction 2018, Game and Entertainment Technologies and Computer Graphics, Visualization, Computer Vision and Image Processing. Red Hook, NY: International Association for Development of the Information Society, 93100(2018).

2. D. Bögenhold, R. Klinglmair, F. Kandutsch, Solo Self-Employment, Human Capital and Hybrid Labour in the Gig Economy. Foresight and STI Governance, 11(4), 23-32(2017). DOI: 10.17323/2500-2597.2017.4.23.32.

3. E.A. Khalimon, M.N. Guseva, I.Z. Kogotkova, I.S. Brikoshina, Digital economy, innovation, information infrastructure, research and development, security, priority projects and programs. In Mantulenko, V. (Ed.), Proceedings of the International Scientific Conference "Global Challenges and Prospects of the Modern Economic Development". The European Proceedings of Social \& Behavioural Sciences 
EpSBS, London: Future Academy (57) 199-213(2018). DOI: 10.15405/epsbs.2019.03.21.

4. E.A. Saveleva, I.V. Bogatyreva? Opportunities of digital economy: Flexible organization of labor. In V. Mantulenko (Ed.), Proceedings of the International Scientific Conference "Global Challenges and Prospects of the Modern Economic Development". The European Proceedings of Social \& Behavioral Sciences EpSBS, London: Future Academy. (57) 407-415(2019). DOI: 10.15405/epsbs.2019.03.41.

5. N.S. Zagrebel'naya, E.R. Bostoganashvili, Human resources management in the digital economy. Economics: Yesterday, Today, Tomorrow, 9(1A), 374-384(2019). [in Rus.].

6. R. Fenech, P. Baguant, D. Ivanov, The Changing Role of Human Resource Management in an Era of Digital Transformation. Journal of Management Information and Decision Sciences. Weaverville, 22 (2)1-10(2019).

7. D. Bersin, B. Pelster, J. Shwartz, B. van der Vyver, New game rules in digital epoch. "Deloitte" research "International trends in the sphere of personnel management”. . (2017). Retrieved from: https://www2.deloitte.com/content/dam/Deloitte/ru/Documents/humancapital/russian/hc-2017-global-human-capital-trends-gx-ru.pdf. Accessed: 01.10.19. [in Rus.].

8. O. Osipova, A. Artamonov, Development of the workforce potential of the state company employees in the new industrialization of Russia. In Y. Silin, Y. Animitsa, E. Dvoryadkina, V. Blaginin (Eds.), Proceedings of the 2nd International Scientific conference on New Industrialization: Global, national, regional dimension (SICNI 2018). Advances in Social Science, Education and Humanities Research, Paris: Atlantis Press. 240 (2019). DOI: 10.2991/sicni18.2019.77.

9. D.K. Zakharov Cloud technologies in the personnel management system. Vestnik Universiteta (5) 190-196(2016). [in Rus.].

10. N.F. Altukhova, E.V. Vasileva, M.V. Mirzoyan, Competence-based approach to managing staff in public administration on the basis of ontologies. Business Informatics, 1 (43), 17-27(2018). DOI: 10.17323/1998-0663.2018.1.17.27. [in Rus.].

11. Z.F. Mingazov, M.I. Prygunova, Feature of application of an integrated approach to automation of the solution of tasks of human resource management in corporations. Scientific Works of the Center of Advanced Economic Research (12) 61-65(2017). [in Rus.].

12. O. Osipova, Digital transformation of personnel management services International Conference on Digital Transformation in Logistics and Infrastructure (ICDTLI 2019). Atlantis Highlights in Computer Sciences. 1. Published by Atlantis Press. 327-329(2019). DOI: https://doi.org/10.2991/icdtli-19.2019.56

13. E.Yates, Cr. Murray, The Future of HR: can HR develop the skills needed to survive?»(2018)Retrieved from:

https://pwc.blogs.com/the_people_agenda/2018/10/the-future-of-hr-can-hrdevelop-the-skills-needed-to-survive.html_Accessed: 23.04.20. [in Rus.].

14. B. A.Vineeta, Human resource analytics. South Asian Journal of Marketing \& Management Research. 7 (5) 68-77(2017). DOI: 10.5958/2249-877X.2017.00031.5

15. E. Flores, X. Xu, Y. Lu, "Human Capital 4.0: a workforce competence typology for Industry 4.0", Journal of Manufacturing Technology Management, 31 (4) 687703(2020)/ https://doi.org/10.1108/JMTM-08-2019-0309

16. A. DiRomualdo, D. El-Khoury, F. Girimonte, HR in the digital age: how digital technology will change HR's organization structure, processes and roles // 
Strategic HR Review, 17(5)234-242(2018). https://doi.org/10.1108/SHR-08-20180074

17. S. Lam, B. Hawkes, From analytics to action: how Shell digitized recruitment, Strategic HR Review, 16(2) 76-80(2017). https://doi.org/10.1108/SHR-01-20170005

18. A.V. Vasilchikov, G.P. Gagarinskaya, T.N. Obushchenko, The recruiter's competence model in the era of technology and digital economy // Labour economics. 5 (4) 959-974 (2018). DOI: 10.18334/et. 5. 4. 39652

19. I. Ivanova, O. Osipova, V. Pulyaeva, Evolution of process of automation of HRdepartments of russian organizations. The European Proceedings of Social and Behavioural Sciences EpSBS. GCPMED- 2019 II International Scientific Conference "Global Challenges and Prospects of the Modern Economic Development" 998-1005(2019).

ISSN: 2357-1330.

DOI:

10.15405/epsbs.2020.03.144 